\title{
INTERIM REPORT
}

Report issued to U.S. Department of Energy

Office of Energy Research/ Environmental Management Science Program

October 15,1997

\section{Quantifying Silica Reactivity in Subsurface Environments: \\ Reaction Affinity and Solute Matrix Controls on Q uartz and $\mathrm{SiO}_{2} \mathrm{G}$ lass \\ Dissolution Kinetics}

Principal Investigator:

Patricia M. Dove, Assistant Professor

School of Earth and Atmospheric Sciences

Georgia Institute of Technology

Atlanta, Georgia 30332 


\section{PREVIOUS (RECENT) WORK}

To date, a central focus of our research efforts has been to gain an understanding of silica-water interactions in terrestrial weathering environments. A knowledge of $\mathrm{SiO}_{2}$ behavior is central to quantifying microscopic as well as global weathering processes in natural and engineered Earth Systems. The long term goal of this effort is to develop a mechanistically-based predictive model that quantifies the reactivity of silica in complex fluid compositions. Early work by Dove and Crerar (1990), Dove and Elston (1992), and Dove (1994) established that low concentrations of the major cations found in natural waters (sodium and potassium) significantly enhance the dissolution kinetics of quartz. This was an important finding because the geochemical community had previously assumed that rates measured in deionized water were adequate to describe silica reactivity in all solution compositional environments. Since then, my research group and I have extended our knowledge of the rates and mechanisms by which solutes modify silica reactivity.

In recent work with rate-enhancing solutes, we have shown that alkaline earth cations also enhance the dissolution kinetics of quartz and possibly most other polymorphs. Thus, the four major solutes (sodium, potassium, magnesium and calcium) found in natural waters enhance silica reactivity. We have been able to pull these effects together and show that these cations have systematic and predictable behavior when correlated with aqueous solvation properties (Dove and Nix, 1997). Combining evidence, we propose that electrostatic attraction of the hydrated cations to the negatively charged surface causes indirect enhancement of $\mathrm{Si}-\mathrm{O}$ bond rupture rates by modifying the frequency of solvent exchange, or the interfacial water structure. In a further step towards understanding silica reactivity in solutions that better approximate natural fluids, Dove (in prep.) has determined quart dissolution rates in solutions containing dilute mixtures of the alkali (IA) and alkaline earth (IIA) cations. The results show that dissolution rates are not a linear combination of the bulk concentrations of cations in solution; rather, rates are disproportionately controlled by the cation with the smallest rate-enhancing effect. The physical model proposes that dissolution rates are determined by the ability of each type of cation to enhance rates and their relative concentrations at the mineral surface. These findings are leading to a competitive sorption model that predicts that dissolution rates in natural waters are likely regulated by the alkaline earth 
cations because of their greater surface interaction strengths. To my knowledge, it is the first model to quantify silica reactivity in a solute mixture.

A second aspect of our interest in silica-water interactions is focused upon the controls manifested by those solutes that are known to inhibit rates of $\mathrm{SiO}_{2}$ dissolution. In freshwater and marine systems, the most important of these solutes is the aluminum ion but to date, estimates of the effect of aluminum on silica reactivity are unconstrained. There are continuing discussions of whether aluminum modifies silica reactivity through changes in apparent solubility or kinetics. To gain an understanding of aluminum controls on silica reactivity, we are determining the kinetics of quartz dissolution in characterized Al-bearing solutions. This is yielding particularly interesting new information because the literature has widely accepted the (unverified) notion that aluminum is an extremely strong inhibitor of silica dissolution. However, our measurements of quartz dissolution rates in ambient and hydrothermal solutions are showing that while rates decrease sharply with the introduction of only a few micromoles of aluminum, the magnitude of this inhibition is much less than suggested by previous studies. While the effect of aluminum is strongly $\mathrm{pH}$-dependent, solutions containing $\mathrm{Al}$ concentrations to 300 micromoles decrease rates by a factor of only 10 at $\mathrm{pH} 4$. Further, silica reactions in the presence of aluminum ions acquire sharply higher energies of activation. A detailed explanation for this behavior is not immediately forthcoming as two competing hypotheses have emerged. In continuing work, we will design new spectroscopic experiments to specifically test the probable models for behavior. 


\section{MOTIVATIONS FOR INVESTIGATIONS OF SILICA GLASS REACTIVITY}

A relatively new branch of our research arises from the unique position of $\mathrm{SiO}_{2}$ as the compositional endmember to the broad class of silicate minerals and glasses. A knowledge of fundamental controls on the reactivity of simple $\mathrm{Si}-\mathrm{O}$ bonded phases is the baseline of behavior for understanding highly complex silica phases. In the Earth, the silicate minerals comprise $>70 \%$ of the crust and dominate virtually every subsurface system. More importantly for the goals of this EMSP project, the silicates are important because compositionally complex glasses will become the front line of defense in containing radioactive wastes in the nation's long term and interim storage strategies. We have begun to investigate relationships between $\mathrm{SiO}_{2}$ glass structure and dissolution rates in aqueous solutions. Again, our approach is to quantify kinetic behavior in characterized conditions and establish the larger principles that govern the behavior of glassy $\mathrm{SiO}_{2}$ materials. In the long term, we plan to systematically introduce new elemental constituents and to build up a sophisticated model of silicate mineral and glass reactivity.

\section{This Report}

We report the preliminary results of our experiments on the dissolution behavior of vitreous silica $\left(\mathrm{v}-\mathrm{SiO}_{2}\right)$ into aqueous solutions of variable $\mathrm{pH}$ and ionic strength. Our experiments are being conducted in mixed flow reactors with a high circulation rate that simulates constant-stirred conditions, the efficacy of which we discuss below. Our preliminary results indicate that $\mathrm{v}-\mathrm{SiO}_{2}$ dissolves into aqueous solutions approximately two orders of magnitude more quickly than crystalline silica (e.g., quartz). With additional experiments, we will utilize the dissolution rate data as a framework for understanding the behavior of waste glass compositions in the subsurface.

In other work related to our studies of glass reactivity, we have written one book chapter that will be published as part of a proceedings for the CEA/VALRHO international nuclear waste disposal conference held in Mejannes le Clap, France. In separate work, we presently writing a second book chapter for the volume entitled Adsorption on Silica Surfaces. (see attached) 


\section{METHODS}

\section{Experimental design}

A schematic diagram of the mixed flow system used in our glass dissolution studies is shown below (Figure 1). The reactor design is based upon the mixed flow methods introduced by Rimstidt and Dove (1986) and Dove and Crerar (1990) for studies of mineral-water interaction rates. The reactor vessels were fashioned from solid rods of either clear acrylic or polycarbonate. The two main pieces of the reactor screw together to form a cylinder two inches in diameter and approximately four inches high (Figure 2). The sample chamber consists of a ring (either acrylic or polvcarbonate) that is seated inside the reactor between the top and bottom pieces. At the bottom and top of the sample holder are a gasket and a piece of nylon mesh that prevents the sample from moving. The relatively large diameter of the sample holder ( 1 inch ID) allows the starting material to form a thin disk-like layer through which the solution. This minimizes flow dispersion and other hydrodynamic artifacts. The reactors are immersed in a 22 liter water bath that is kept at constant temperatures $\left(60^{\circ} \mathrm{C}\right.$ in current experiments). Solutions were fed into the system from plastic syringes mounted

\section{Figure 1: Schematic of the Mixed-flow System}

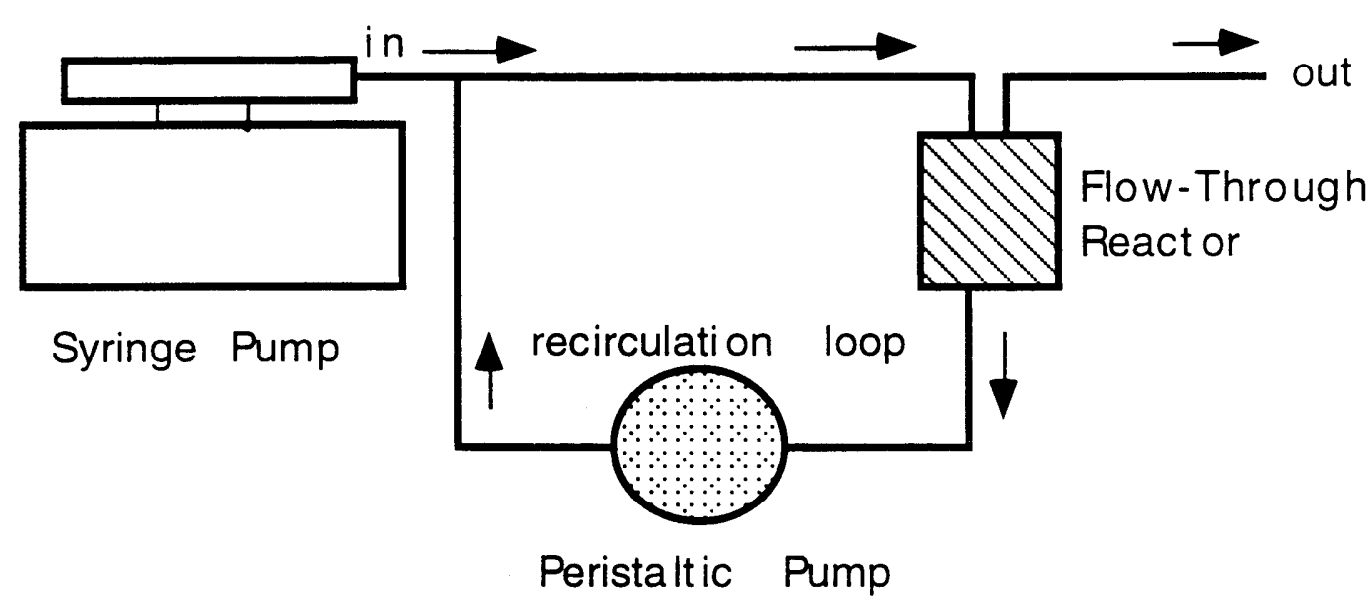

on a Harvard PHD-2000 syringe pump with injection rates of 6 microliters $\mathrm{min}^{-1}$. Solutions are recirculated from the reactors to the point of injection by peristaltic pumps. Recirculation rates are 2.5 to $3.0 \mathrm{ml} \mathrm{min}^{-1}$, which is $>15 x$ the injection rate, 
the requirement for a constant stirred approximation (Dove and Crerar, 1990). The volume of the entire system is approximately $25 \mathrm{ml}$. This translates to a reaction time of approximately 21 days to steady-state conditions (for 7 residence times). The outflow solution from each reactor is sampled once per day and the silica concentration is measured by the molybdate blue colorimetric method. Absorption intensities were measured at the 810 nanometer wavelength and concentrations were determined using standards of known $\mathrm{Si}$ concentrations that were freshly prepared for each analysis session.

\section{Figure 2 : Flow-Through React or Schematic}

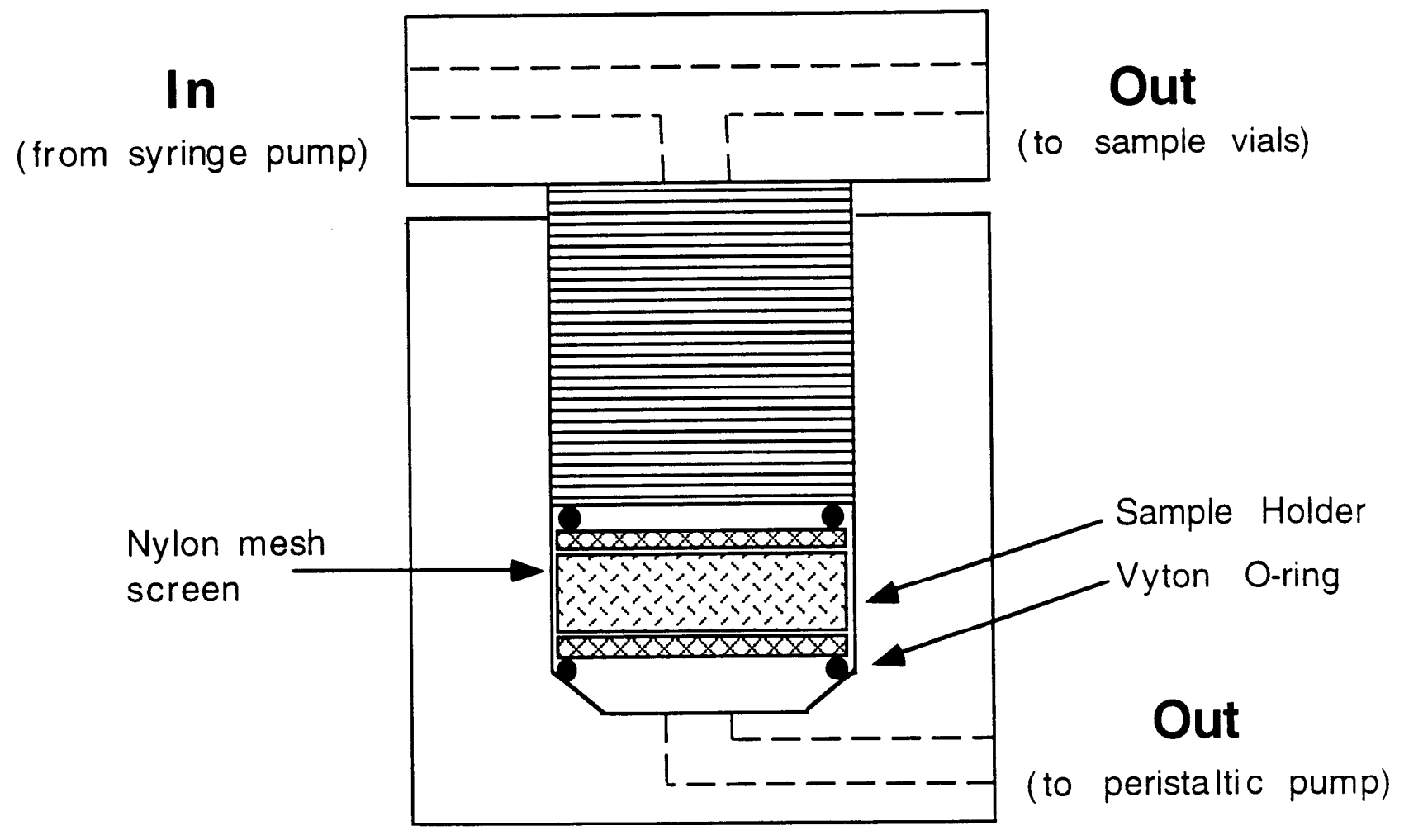

\section{Mixed Flow Reactors in Geochemical Kinetics}

As discussed elsewhere, mixed flow reactors have important advantages over other types of reactors, such as plug flow or batch (c.f., Dove and Rimstidt, 1985; Dove and Crerar, 1990). The principal advantage of mixed flow reactors is that reaction rates can be easily measured at steady state conditions without resorting to 
fitting concentration vs. time (batch) or concentration vs. column length (plug flow) data to presumed rate laws. We are particularly concerned with experiments using batch reactors in which dissolution rates are calculated using the 'initial rate' method. As we show below, the initial concentration of Si may depend strongly on the dissolution of fine-grained particles and sharp edges, thereby leading to spurrious conclusions regarding the true rate of dissolution. Because mixed flow reactors have a uniform fluid composition throughout the system, direct measurement of the reaction rate is possible. Furthermore, because the fluid composition has a constant chemical affinity, the extent of reaction is also easily determined. In contrast, plug flow reactors must account for a continuous change in aqueous and solid chemical composition and reaction rates from reactor input to output. The second significant advantage of mixed flow reactors is that diffusion limited conditions, especially those in which reaction and diffusion rates are nearly equal, are more easily identified and avoided. In the case of our system, constant stirred conditions are simulated by setting recirculation rates fast ( $>15 x)$ compared to the rate of injection. The solution is forced past stationary grains of the starting material thereby minimizing the accumulation of amorphous products on the surface and preventing mutual abrasion of the grains (Figure 2). Equally important, the flow of the solution past the grains of silica reduces the thickness of the boundary layer at the mineral/ solution inferface (Dibble and Tiller, 1981; Aagaard and Helgeson, 1982), affording direct measurement of dissolution rates with few to no experimental artifacts. The final advantage is that mixed flow reactor systems are flexible, allowing us to adjust solution injection rates appropriate to the fluid residence times of our system. In the case of vitreous silica, which is more reactive than its crystalline polymorphs, we can use shorter residence times so that the extent of reaction is comparable to that of quart and small.

\section{Starting materials}

The glass material used in the first round of experiment was obtained from Quartz Scientific Inc. This $\mathrm{v}^{-\mathrm{SiO}_{2}}$ contains reported impurities (including Al, B, alkali metals, and alkaline earths) of $\leq 5 \mathrm{ppm}$ each. To prepare a sample for dissolution experiments, the starting glass material was ultrasonically cleaned in methanol and then placed into a hydrogen peroxide (30\% vol.) bath overnight. The $\mathrm{V}-\mathrm{SiO}_{2}$ was then soaked for three days in a $10 \%$ (vol.) nitric acid solution to remove any surficial impurities. The material was then ground in a ball mill using a sintered alumina ceramic and then sieved to obtain the $<60$ to $>80$ mesh (200 to 300 
micron) fraction for use in the experiments. This material was rinsed in deionized water and then the solutions decanted at least 12 times in an attempt to remove any fine-grained particles that may have adhered to the desired size fraction. Inspection of the starting material under binocular microscope reveals that the majority of the grains are elliptically-shaped shards with prominent conchoidal fractures. The measured surface area, performed using BET methods with Ar as the adsorbate, is $0.0314 \mathrm{~m}^{2} \mathrm{~g}^{-1}$ (compare with the typical $0.02 \mathrm{~m}^{2} \mathrm{~g}^{-1}$ of crystalline quart).

\section{RESULTS}

The results of four early experiments conducted at $\mathrm{pH} 4$ are shown in Figure 3. Experiments 1 and 2 contained 0.05 molal $\mathrm{NaCl}$ whereas numbers 3 and 4 contained no dissolved solutes. Further, the material in Experiment 1 received an additional pretreatment step. The importance of this additional step is shown in the figure where Experiment 1 reaches a steady state concentration of silica early and maintains this concentration over the duration of the experiments. In contrast, the concentration of $\mathrm{Si}$ in Experiments 2, 3, and 4 increase rapidly, reach a peak concentration, and then decline to steady values over time. We attribute this difference in behavior to the dissolution of small amounts of reactive components, such as sharp edges and fines, that are remaining in the starting materials of Experiments 2, 3, and 4. We are presently working out the details of an optimized pretreatment program. Note, however, that all four experiments reach a steady state concentration of silica.

Dissolution rates for the four experiments were calculated from the expression:

$$
r_{j}=\left(m_{j}\right) u /\left(A_{r}\right)\left(m_{r}\right)
$$

where $\quad r_{j}=$ the rate of appearance of product $j$ (in this case, $\mathrm{Si}$ ) at outlet conditions per unit area of reactant $\left(\mathrm{mol} \mathrm{m}^{-2} \mathrm{~s}^{-1}\right)$

$$
\begin{aligned}
& \mathrm{m}_{\mathrm{j}}=\text { molal outlet concentration }\left(\mathrm{mol} \mathrm{kg}^{-1}\right) \\
& \mathrm{u}=\text { mass flow rate }\left(\mathrm{kg} \mathrm{s}^{-1}\right) \\
& \mathrm{A}_{\mathrm{r}}=\text { total surface area per gram of solid in reactor }\left(\mathrm{m}^{2} \mathrm{~g}^{-1}\right) \\
& \mathrm{m}_{\mathrm{r}}=\text { mass of solid in reactor }(\mathrm{g})
\end{aligned}
$$

The calculated $\log r_{j}$ for the four experiments are:

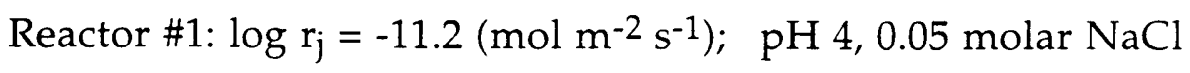

Reactor \#2: $\log \mathrm{r}_{\mathrm{j}}=-11.0 ; \quad \mathrm{pH} 4,0.05$ molar $\mathrm{NaCl}$ 
$\begin{array}{ll}\text { Reactor \#3: } \log r_{j}=-10.7 ; & \mathrm{pH} 4, \text { no dissolved solutes } \\ \text { Reactor \#4: } \log r_{j}=-10.8 ; & \mathrm{pH} 4, \text { no dissolved solutes }\end{array}$

These dissolution rates are approximately 2 orders of magnitude faster $\left(\log r_{j}\right.$ $=-12.5 \mathrm{~mol} \mathrm{~m} \mathrm{~m}^{-1}$ ) than that calculated for crystalline quartz at $60{ }^{\circ} \mathrm{C}$ using equation [16] from Dove (1994). Although we consider these data preliminary, they are consistent with the Mazer and Walther (1994) dissolution rate of $\log r_{j}=-10.5 \mathrm{~mol}$ $\mathrm{m}-2 \mathrm{~s}-1$ reported for vitreous silica in a pH 4.1 solution at $60{ }^{\circ} \mathrm{C}$. The data are also consistent with our expectation that the dissolution behavior of $\mathrm{v}-\mathrm{SiO}_{2}$ will be similar to that of crystalline quartz; i.e., that sodium chloride solutions has little effect on dissolution rate at low values of pH (see Dove and Elston, 1992).

Figure 3.

Silica Glass, $60^{\circ} \mathrm{C}$

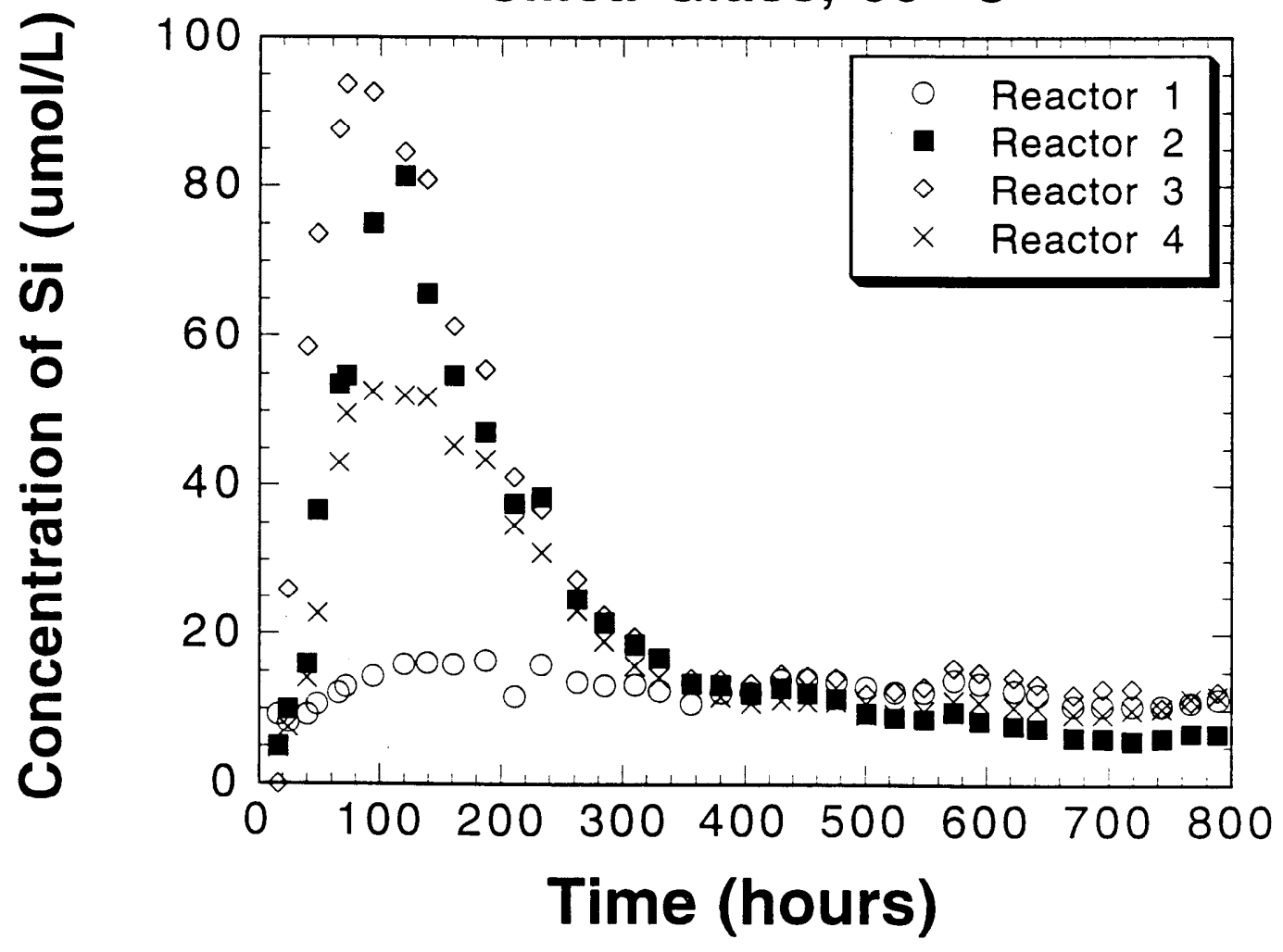




\section{ONGOING INVESTIGATIONS}

We currently are running a matrix of $60^{\circ} \mathrm{C}$ experiments using solution compositions of variable $\mathrm{pH}$ and sodium concentration. These experiments determine the $\mathrm{pH}$-dependence of dissolution of vitreous silica and the effect of an important solute found in natural waters. These data will allow us to begin constructing a larger goup of experiments to measure the the effect of temperature over 25 to $80^{\circ} \mathrm{C}$ to determine activation energies of dissolution and the effect of the important rate-modifying aqueous constituents: the alkali, alkaline earth, aluminum cations. Previous investigations by this laboratory have shown both rate enhancing and inhibiting (Dove and Nix, 1997) effects of dissolved cations in the reacting solutions. These data should be particularly useful in establishing a framework for assessing subsurface waste disposal strategies that utilize glass as the disposal medium.

\section{REFEREN CES}

Aagaard, P and Helgeson, HC (1982) Thermodynamic and kinetic constraints on reaction rates among minerals and aqueous solutions. I. Theoretical considerations. American Journal of Science, 282, 237-285.

Dibble, WE Jr. and Tiller, WA (1981) Non-equilibrium water/ rock interactions--I. Model for interface-controlled reactions. Geochimica et Cosmochimica Acta, 45, 79-92.

Dove, PM (1994) The dissolution kinetics of quartz in sodium chloride solutions at $25^{\circ}$ to $300^{\circ} \mathrm{C}$. American Journal of Science, 294, 665-712.

Dove, PM and Crerar, DA (1990) Kinetics of quartz dissolution in electrolyte solutions using a hydrothermal mixed flow reactor. Geochimica et Cosmochimica Act, 54, 955-969.

Dove, PM and Elston, SF (1992) Dissolution kinetics of quart in sodium chloride solutions: Analysis of existing data and a rate model for $25^{\circ} \mathrm{C}$. Geochimica et Cosmochimica Acta, 56, 4147-4156.

Dove, PM and Rimstidt, JD (1985) Wollastonite hydrolysis in a mixed flow reactor. Geological Society of America Abstract, p. 467.

Dove, PM and Nix, CJ (1997) The influence of the alkaline earth cations, magnesium, calcium, and barium on the dissolution kinetics of quartz. In press: Geochimica et Cosmochimica Acta.

Mazer, JJ and Walther, JV (1994) Dissolution kinetics of silica glass as a function of $\mathrm{pH}$ between 40 and $85^{\circ} \mathrm{C}$. Journal of Non-Crystalline Solids, 170, 32-45. 


\section{PERSON NEL INVOLVED IN THE RESEARCH}

Dr. Patricia Dove (P.I. and Assistant Professor)

Dr. Jonathan Icenhower (Postdoctoral Research Scientist)

Mr. Troy Lorier (undergraduate)

\section{IN VITED TALKS/SEMINARS}

August, 1997, International Nuclear Waste Disposal Conference, CEO-Valrho, France.

\section{PUBLICATIONS}

Dove, P.M. and Icenhower, J. (1997) Kinetic and Thermodynamic Controls on Silica Reactivity: An Analog for Waste Disposal Media; Invited chapter. Commissariat a L'Energie Atomique - Valrho, École D'été. In: Glass: Scientific Research for High Performance Containment (S. Gin, editor).

Dove, PM and Icenhower, J (1997) Water Behavior at Silica Surfaces; Invited Chapter. In: Adsorption on Silica Surfaces (E. Papirer, editor). 